\title{
Extraction Kinetics of Methylene Blue by AOT and DEHPA Reversed Micellar Solution
}

\author{
Takumi KINUGASA*, Takamasa ICHIRYU, Miyuki SHINOHARA and Yasuhiro NISHII \\ Department of Applied Chemistry and Biotechnology, National Institute of Technology, \\ Niihama College, 7-1 Yagumo-cho, Niihama 789-8580, Japan
}

(Received June 27, 2019; Accepted August 29, 2019)

\begin{abstract}
Water pollution in China, Southeast Asia and other developing countries is a major problem, one of which is synthetic dyes contained in industrial wastewater. In this study, we focused on reversed micellar extraction which is promising from the viewpoint of both costs and energy saving, and examined the extraction rate of methylene blue (MB) using sodium bis(2-ethylhexyl)sulfosuccinate (AOT) and di(2-ethylhexyl)phosphate (DEHPA). In the AOT/isooctane system, the overall mass transfer coefficient of the MB extraction, $K_{\mathrm{W}}$, decreased with increasing $\mathrm{NaCl}$ or $\mathrm{KCl}$ concentration. In contrast, in the AOT/2-ethyl-1-hexanol (EHA) and DEHPA/EHA systems, the effect of the $\mathrm{KCl}$ concentration was smaller. For the AOT/(isooctane + EHA) and DEHPA/(isooctane + EHA) systems, the $K_{\mathrm{W}}$ value increased with increasing EHA concentration. However, the dissolution of $\mathrm{MB}$ in the organic solvent cannot be ignored at higher EHA concentrations. At the same concentrations of salt and EHA, the $K_{\mathrm{W}}$ values of the AOT and DEHPA systems were almost the same. The dissociation state of DEHPA changed with $\mathrm{pH}$, and the $K_{\mathrm{W}}$ value decreased with decreasing $\mathrm{pH}$. It was confirmed that the $K_{\mathrm{W}}$ value for MB extraction was determined by the dissociated DEHPA concentration.
\end{abstract}

\section{Introduction}

Most of the wastewater from dye-synthesis plants and from plants for dyeing textiles, leather, pulp and paper contains synthetic dyes. Dyes are required to be weather-, light- and chemical-resistant. Consequently, they are often difficult to be degrade. In addition, even very small amounts of dye induce colors in rivers, lakes, and coastal areas, causing a strong awareness of pollution. Therefore, the development of efficient methods for the dye removal from wastewater is an important issue [1-3].

The Water Pollution Prevention Act of Japan defines certain substances such as mercury and benzene as health-threatening items and emission standards such as $\mathrm{pH}$ and $\mathrm{COD}$ as life environment items, but there are no restrictions on the levels of color in water effluents. Therefore, although the drainage standard is satisfied, there are cases where the coloring component is not treated. In recent years, some local governments have started to regulate colored drainage by ordinance. Also, with the industrial development in China and Southeast Asia, water pollution has become a pressing issue. BOD levels have tended to increase because water treatment measures have been delayed, and in many countries the impact of pollutants on water in the environment exceeds natural resilience. The problem of colored drainage is also becoming prominent, and emission standards of coloring degree have been introduced in countries such as the Philippines and Singapore and in some provinces of Indonesia. 
Colored wastewater is generally subjected to biological treatment by the activated sludge method after flocculation with an inorganic coagulant and a polymer coagulant, and then finally by UV ozone oxidation or activated carbon adsorption [4]. These methods have cost implications arising from the treatment/disposal of aggregates, sludges, activated carbon, etc., from equipment supplies and from the operating costs of the ozone generator. Furthermore, it is not possible to reuse the dye removed from the wastewater in any way.

On the other hand, removal of dyes from wastewater by solvent extraction has been considered recently. Solvent extraction is one of the most popular separation techniques in the chemical industry, and has advantages such as low energy consumption, only requiring simple and inexpensive equipment, ease of continuous operation and scale-up, and high efficiency via choice of the appropriate extractant. The dye in the aqueous solution is transferred to the organic phase containing the extractant and can be recovered by back extraction, making it possible to reuse. Examples of extraction media include ionic liquids $[5,6]$, calix $[n]$ arenes and their derivatives $[7,8]$ and reverse micelles $[9,10]$. Of these, reverse micelles have the advantage of being inexpensive and easy to handle. Reverse micelles are self-assembled aggregates of amphiphilic surfactants in an apolar solvent. The hydrophilic groups are directed towards the interior of the assembly and the hydrophobic groups extend towards the apolar solvent. Nano-sized waterpool is formed in the center of the assembly by solubilizing water, and a water-soluble substance can be incorporated into the waterpools. In reversed micellar extraction, the surfactants that form reverse micelles act as extractants.

In our laboratory, the extraction equilibrium of methylene blue (MB) into the reverse micelles formed by sodium bis(2-ethylhexyl)sulfosuccinate (AOT) has been examined. It was found that MB can be extracted from low salt aqueous solution and can be recovered by stripping into a fresh aqueous solution of high salt concentration [11]. The extraction of MB by di(2-ethylhexyl)phosphate (DEHPA) reverse micelles was also discussed. The formation of DEHPA reverse micelles depends on $\mathrm{pH}$, and it was shown that the extraction of MB under neutral conditions and back-extraction with weak acidity were possible [12].

In the practical application of the solvent extraction to dye removal, it is important to elucidate the extraction kinetics. Some studies have been reported on on mass transfer in reverse micelle extraction of proteins [13,14], amino acids [15,16], peptides [17], antibiotic [18], and so on. In these studies, the mass transfer of each solute was examined based on the double film theory. However, the effects of the types of extractant and organic solvent have not been reported. In this paper, we report the effects of varying operating conditions, such as surfactant and salt concentrations and $\mathrm{pH}$, on the overall mass transfer resistance of $\mathrm{MB}$ using reversed micellar solution formed by AOT/(isooctane + 2-ethyl-1-hexanol (EHA)) and DEHPA/(isooctane + EHA).

\section{Experimental}

Methylene blue (MB), purchased from Kanto Chemical, was used as a representative cationic dye. Sodium bis(2-ethylhexyl)sulfosuccinate (AOT) or di(2-ethylhexyl)phosphoric acid (DEHPA) was used as an anionic surfactant. AOT, obtained from Nacalai Tesque, was used as received, and DEHPA supplied from Daihachi Chemical Ind. Co. was purified by washing alternately with $6 \mathrm{kmol} / \mathrm{m}^{3}$ hydrochloric acid and distilled water three times. The aqueous solutions were prepared by adding the dye to solutions in which $\mathrm{pH}$ were adjusted with buffer and salt concentration, $C_{\mathrm{E}}$, with $\mathrm{NaCl}$ or $\mathrm{KCl}$. Initial concentration of $\mathrm{MB}, C_{W, 0}$, was $2.0 \times 10^{-5} \mathrm{kmol} / \mathrm{m}^{3}$. The organic solutions were prepared by dissolving the surfactant in 2,2,4- 
trimethylpentane (isooctane) and/or 2-ethyl-1-hexanol (EHA).

A stirred transfer cell made of glass shown in Figure 1 was used to measure the overall mass transfer coefficient of MB, $K_{\mathrm{W}}$. Equal volumes $\left(50 \mathrm{~cm}^{3}\right)$ of aqueous and organic solutions were put in the lower and upper sections of the cell, respectively, and the two phases were stirred with turbine blades placed at the center depth of each phase. The stirring speed was $150 \mathrm{rpm}$ which gave no ripples at the interface. At 10 minutes intervals, a given amount of the aqueous phase was sampled by syringe and analyzed using a UV-Vis spectrophotometer (Shimadzu UV1600) to determine the MB concentration in the aqueous phase, $C_{W}$, from the absorbance at $664 \mathrm{~nm}$. The forward extraction rate of MB, $r_{f}$, was expressed as follows.

$$
r_{f}=-\frac{V_{w}}{A} \frac{\mathrm{d} C_{w}}{\mathrm{~d} t}=K_{w}\left(C_{w}-\frac{C_{o}}{m}\right)
$$

where $A$ is the interfacial area between the two phases and $V_{W}$ is the volume of the aqueous phase. The term $C_{O} / m$ can be neglected since the distribution ratio of $\mathrm{MB}, m$, is large under the forward extraction conditions and the MB concentration in the organic phase, $C_{O}$, is small during the initial period of the experiment. Thus, Eq.(1) can be integrated to yield Eq.(2).

$$
\ln \left(\frac{C_{W}}{C_{W, 0}}\right)=-\frac{A}{V_{W}} K_{w} t
$$
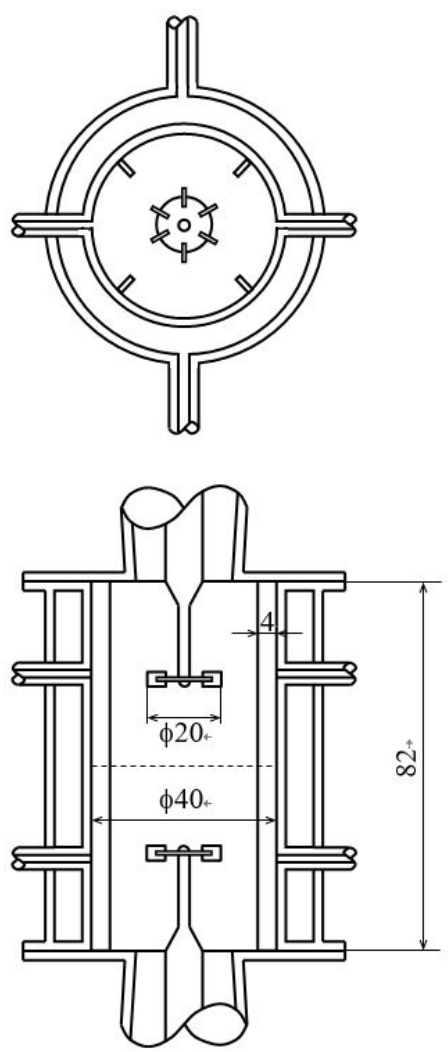

Figure 1. Stirred cell for dye extraction.

The slope of the plot of the left side of Eq.(2) versus time, $t$, gives the overall mass transfer coefficient of $\mathrm{MB}, K_{\mathrm{W}}$. In this experiment, water solubilization to the organic phase occurred as MB was extracted, and reverse micelles were formed over time.

\section{Results and Discussion}

\subsection{Extraction kinetics of MB by AOT}

Figure 2 shows the results of plotting the $\ln \left(C_{W} / C_{W, 0}\right)$ values obtained from MB concentration against time, $t$, under typical experimental conditions. A linear relationship holds approximately for each AOT concentration, and it can be seen that Eq.(2) applies.

Figure 3 shows the overall mass transfer coefficient of $\mathrm{MB}, K_{\mathrm{W}}$, from $\mathrm{NaCl}$ or $\mathrm{KCl}$ aqueous solution to AOT/isooctane reversed micellar solution $\left(C_{\mathrm{EHA}}=0\right)$. As the concentration of AOT was increased, the value of $K_{\mathrm{W}}$ increased and then reached a plateau. The $K_{\mathrm{W}}$ value obtained for $\mathrm{NaCl}$ was larger than that for $\mathrm{KCl}$, and the values for both decreased with the salt

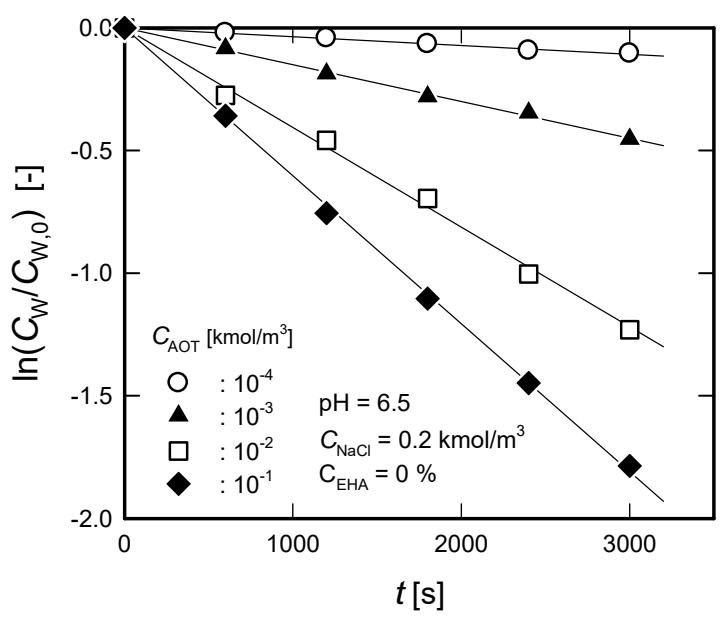

Figure 2. Plots of $\ln \left(C_{W} / C_{W, 0}\right)$ versus time. 

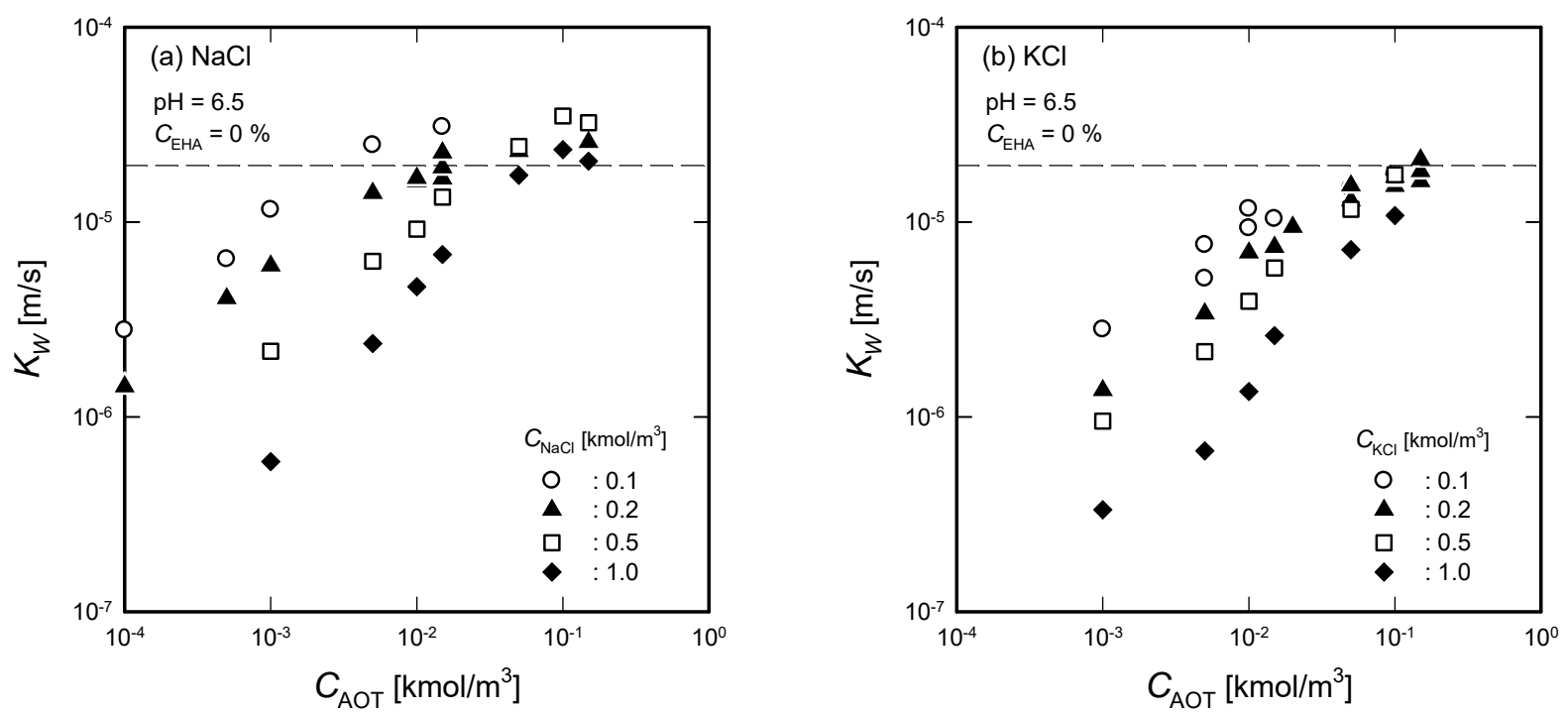

Figure 3. Effect of AOT and salt concentration on overall mass transfer coefficient of $\mathrm{MB}$ from (a) $\mathrm{NaCl}$ and (b) $\mathrm{KCl}$ solution to $\mathrm{AOT} /$ isooctane. The dashed line shows the aqueous film mass transfer coefficient.

concentration. Such behavior of dye extraction using AOT has been also reported for the extraction equilibrium and can be explained by an electrostatic screening effect [11]. The aqueous film mass transfer coefficient of MB, $k_{\mathrm{W}}$, was estimated as $1.9 \times 10^{-5} \mathrm{~m} / \mathrm{s}$ from the transfer of $I_{2}$ from an aqueous to an organic phase [19]. The constant value of $K_{\mathrm{W}}$ at higher AOT concentrations was in agreement with the $k_{\mathrm{W}}$ value, which suggests the transfer rate of $\mathrm{MB}$ is controlled by the diffusion in the aqueous boundary film.

Figure 4 shows the effect of $\mathrm{AOT}$ and $\mathrm{KCl}$ concentration on the $K_{\mathrm{W}}$ value of the $\mathrm{MB}$ extraction from $\mathrm{KCl}$ solution to $\mathrm{AOT} / \mathrm{EHA}$ solution $\left(C_{\mathrm{EHA}}=\right.$

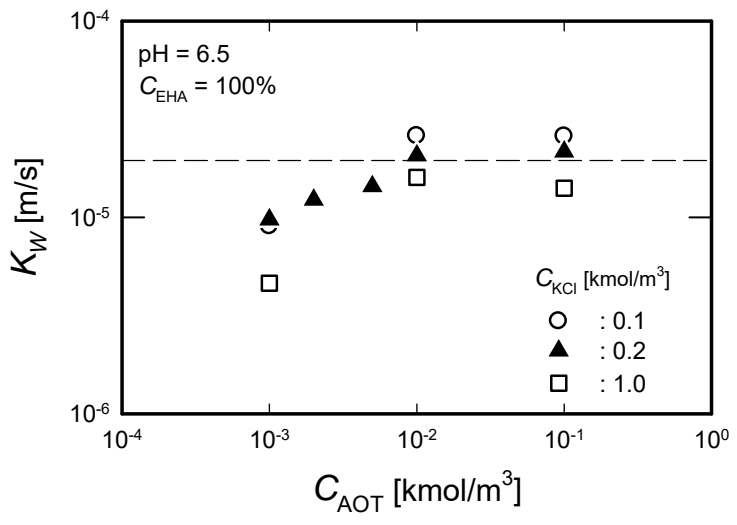

Figure 4. Effect of AOT and $\mathrm{KCl}$ concentration on overall mass transfer coefficient of $\mathrm{MB}$ from $\mathrm{KCl}$ solution to AOT/EHA. $100 \%)$. It is known that EHA prevents the leakage of DEHPA from an organic phase to an aqueous phase [12]. Although the addition of EHA into an AOT/ isooctane system is not necessary, the effect of the organic solvent was examined in order to compare the AOT and the DEHPA systems. In the AOT/EHA system, the $K_{\mathrm{W}}$ values were larger than those of the AOT isooctane system, and the effect of the aqueous $\mathrm{KCl}$ concentration on the $K_{\mathrm{W}}$ value was small. Moreover, in Figure 5, the effect of the EHA concentration, $C_{\mathrm{EHA}}$, on the $K_{\mathrm{W}}$ value from $\mathrm{KCl}$ solution to $\mathrm{AOT} /($ isooctane + EHA) solution was shown. The higher the EHA concentration, the larger the $K_{\mathrm{W}}$ value. EHA is more polar solvent than isooctane, and then the dissolution of $\mathrm{MB}$ in an organic solvent was concerned. Table 1 shows the extraction ratio of MB to the isooctane $+\mathrm{EHA}$ solution without DEHPA. Below $50 \%$ EHA, MB was hardly soluble in the organic phase, but at $>50 \%$ EHA concentration the solubility was increased and reached $14.2 \%$ at $100 \%$ EHA. On the other hand, as shown in Figure 4, the $K_{\mathrm{W}}$ value showed a large increase even at EHA concentration of $50 \%$ or less. Therefore, 
it is considered that the $K_{\mathrm{W}}$ value increased as the EHA concentration increased, since the species in which AOT binds to $\mathrm{MB}$ is more likely to be distributed to highly polar EHA rather than being dissolved in the organic phase by MB alone. The dissolution of MB in the organic solvent would be disadvantageous, given the back extraction, so the EHA concentration should be less than $50 \%$.

\subsection{Extraction kinetics of MB by DEHPA}

In Figure 6, the effect of DEHPA concentration on the $K_{\mathrm{W}}$ value of the extraction of MB from aqueous $\mathrm{KCl}$ solution to DEHPA/EHA reversed micellar solution $\left(C_{\mathrm{EHA}}=100 \%\right)$ is shown. As in the AOT system, the $K_{\mathrm{W}}$ value increased with increasing DEHPA concentration, and eventually reached the value of the aqueous film mass transfer coefficient $k_{\mathrm{W}}$. When the

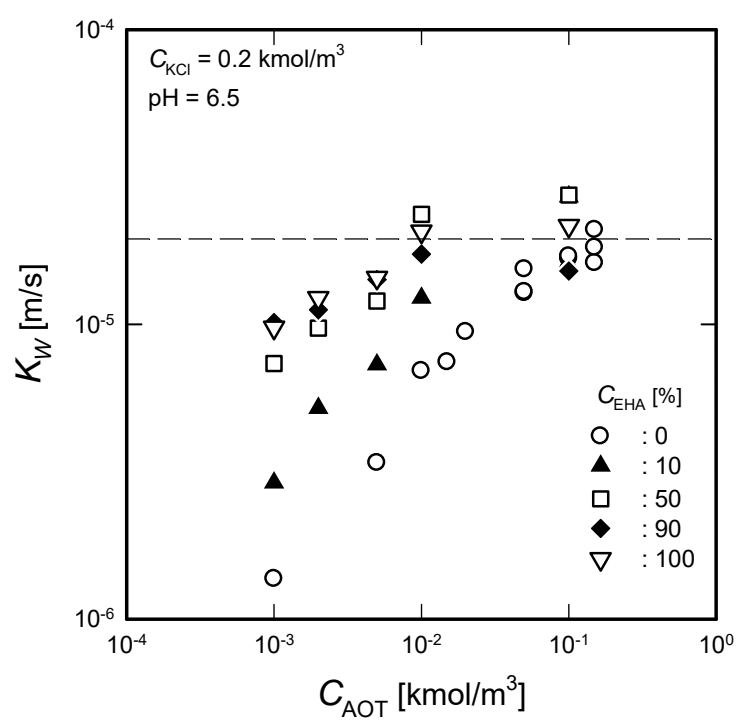

Figure 5. Effect of EHA concentration on overall mass transfer coefficient of MB from $\mathrm{KCl}$ solution to $\mathrm{AOT} /($ isooctane + EHA). EHA was used as the organic solvent, the effect of $\mathrm{KCl}$ concentration on the $K_{\mathrm{W}}$ value was small in the DEHPA system, as in the AOT system. It is presumed that the electrostatic screening effect between the MB and extractant was weakened because EHA is more polar than isooctane. Figure

7 shows the effect of the EHA concentration on the $K_{\mathrm{W}}$ value from $\mathrm{KCl}$ solution to DEHPA/(isooctane + EHA) Table 1. Extraction ratio of MB to isooctane + EHA solution without DEHPA. $C_{W, 0}=2.0 \times 10^{-5} \mathrm{kmol} / \mathrm{m}^{3}, \mathrm{pH}=8.5, C_{\mathrm{KCl}}$ $=0.2 \mathrm{kmol} / \mathrm{m}^{3}$.

\begin{tabular}{cccc}
\hline$C_{\mathrm{EHA}}[\%]$ & $E[\%]$ & $C_{\mathrm{EHA}}[\%]$ & $E[\%]$ \\
\hline 0 & 0 & 70 & 1.2 \\
10 & 0 & 80 & 2.4 \\
20 & 0 & 90 & 6.4 \\
50 & 0.2 & 100 & 14.2 \\
\hline
\end{tabular}

solution. The $K_{\mathrm{W}}$ value increased with increasing the EHA concentration. Comparing Figures. 4 and 5 with Figures. 6 and 7, the $K_{\mathrm{W}}$ value of DEHPA system was almost the same as that of AOT under the conditions of the same concentrations of EHA and KCl. It has been reported that there are significant differences in the size and shape between AOT and DEHPA reverse micelles [20]. However, the above results show that the characteristics of reverse micelles do not affect the extraction rate of MB. Therefore, it was shown that the extraction rate of MB by AOT or DEHPA is governed by the electrostatic interaction between the MB and extractant, regardless of the size and shape of reverse micelles formed. In the previous paper [12], it was reported that MB was solubilized as a MBDEHPA complex in the organic solution and/or entrapped in the waterpool of a reverse micelle at $\mathrm{pH}$ values above 5.5. From the kinetic study, it was suggested that the positively charged MB was bound to the negatively charged head group of the extractant and solubilized in the organic phase as the MB-extractant complex, rather than MB being taken up by the reverse micelles at the interface. Then the MB-extractant complex may form the reverse micelle containing MB with free extractants. 


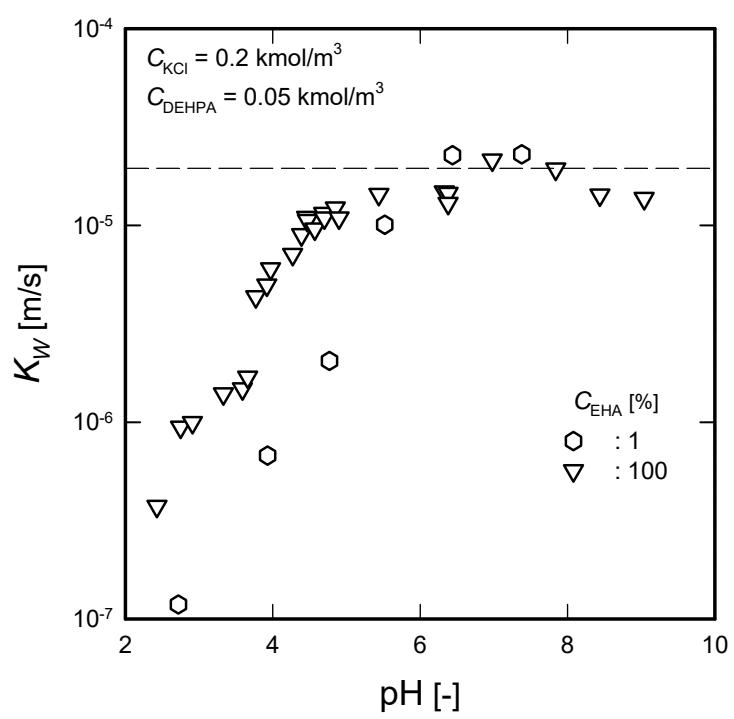

Figure 6. Effect of DEHPA and $\mathrm{KCl}$ concentration on overall mass transfer coefficient of $\mathrm{MB}$ from $\mathrm{KCl}$ solution to DEHPA/EHA.

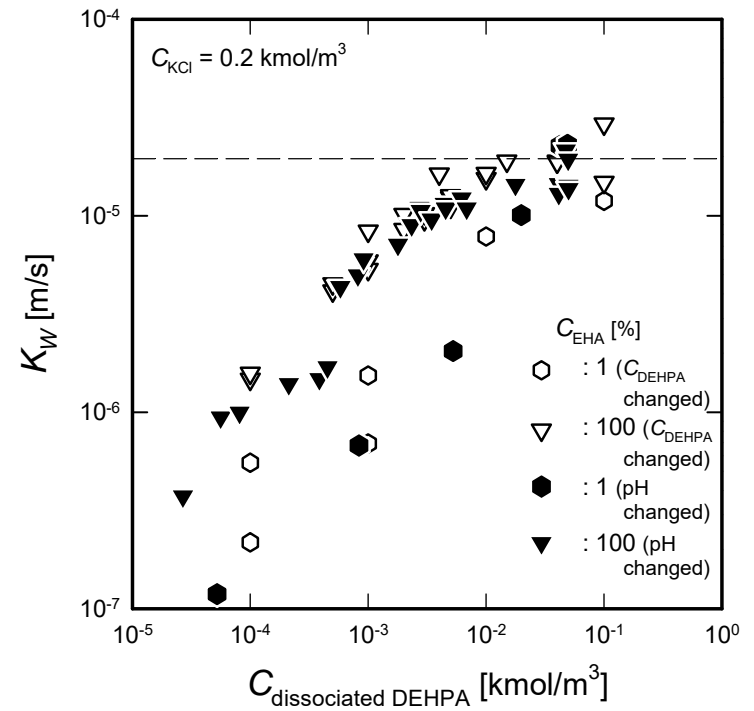

Figure 7. Effect of EHA concentration on overall mass transfer coefficient of MB from $\mathrm{KCl}$ solution to DEHPA/(isooctane + EHA).

Figure 8 shows the effect of $\mathrm{pH}$ on the $K_{\mathrm{W}}$ value of the MB extraction to DEHPA/(isooctane + EHA) solution. The $K_{\mathrm{W}}$ value was greatly increased with increasing $\mathrm{pH}$ between $\mathrm{pH} 2$ and 6 . Since the $\mathrm{p} K_{a}$ value of DEHPA is 5.7 [21], the increase in $\mathrm{pH}$ results in the dissociation of DEHPA. Conversely, it is considered that the extraction rate of MB decreased because the number of negatively charged DEHPA molecules decreased as the $\mathrm{pH}$ decreased. The dissociated DEHPA concentration was calculated from the results shown in Figure 7 and 8, and the effect on the $K_{\mathrm{W}}$ value was plotted in Figure 9. Under the conditions shown in

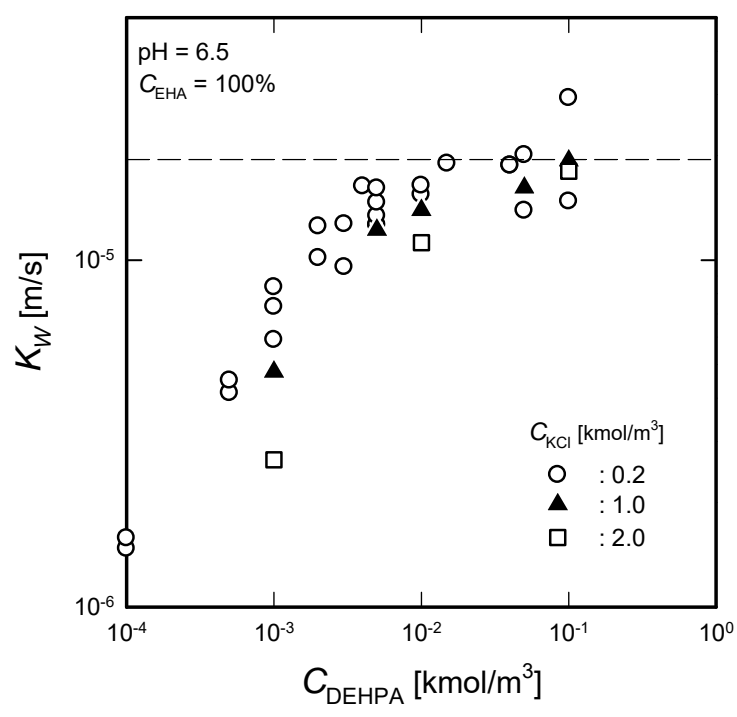

Figure 8. Effect of $\mathrm{pH}$ on overall mass transfer coefficient of $\mathrm{MB}$ from $\mathrm{KCl}$ solution to DEHPA/(isooctane + EHA).

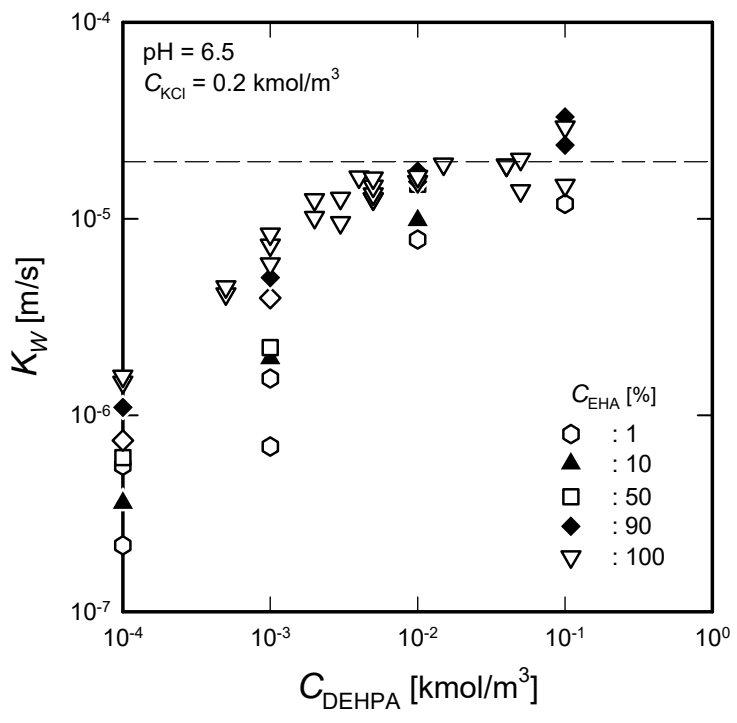

Figure 9. Effect of dissociated DEHPA concentration on overall mass transfer coefficient of $\mathrm{MB}$ from $\mathrm{KCl}$ solution to DEHPA/(isooctane + EHA). 
Figure 7, the dissociated DEHPA concentration was varied by changing $C_{\mathrm{DEHPA}}$ at $\mathrm{pH}=6.5$, and under the conditions shown in Figure 8, the dissociated DEHPA concentration was varied by changing $\mathrm{pH}$ at $C_{\mathrm{DEHPA}}=$ $0.05 \mathrm{kmol} / \mathrm{m}^{3}$. The $K_{\mathrm{W}}$ values in both cases were nearly equal. This indicate that the dissociated DEHPA extracted MB by electrostatic attraction, and dissociated DEHPA neither promoted nor suppressed the MB extraction.

\section{Conclulsion}

A study of the extraction kinetics of methylene blue, MB, with AOT and DEHPA reversed micellar solution has provided results on the effects of operating conditions on the overall mass transfer coefficient, $K_{\mathrm{W}}$. The $K_{\mathrm{W}}$ value of the MB extraction decreased with increasing the salt concentration due to the electrostatic screening effect between the MB and extractant. The decreasing tendency of the $K_{\mathrm{W}}$ values was higher in the isooctane system than in the EHA system. It is considered that the electrostatic screening effect was weaker in the higher polar solvent, EHA. In both the AOT and DEHPA systems, the higher the EHA concentration, the larger the $K_{\mathrm{W}}$ value. This indicates that the MB-extractant species distributed readily to the polar EHA. The solubility of MB in the organic solvent without extractant increased rapidly when the EHA concentration exceeded $50 \%$. In consideration the back extraction, it is desirable to have an EHA concentration $50 \%$ or less. The $K_{\mathrm{W}}$ values of the AOT and DEHPA systems were nearly equal under the same operating conditions. It was found that the extraction rate of MB by these extractants was not dependent on the formation of reverse micelles. The $K_{\mathrm{W}}$ value was lowered because the dissociated DEHPA concentration decreased with decreasing $\mathrm{pH}$ at a constant DEHPA concentration. The $K_{\mathrm{W}}$ value was determined by dissociated DEHPA concentration, which was controlled by varying the DEHPA concentration and $\mathrm{pH}$. Thus, $\mathrm{MB}$ extraction was dominated by the electrostatic attraction with the negative charge of the extractant and was not affected by the type of the extractant and the presence of undissociated species of the extractant.

\section{References}

1) V. Kathersan, J. Kansedo, S. Y. Lau, J. Environ. Chem. Eng., 6, 4676-4697 (2018).

2) Y. Zhou, J. Lu, Y. Zhou, Y. Liu, Environ. Pollution, 252, 352-365 (2019).

3) K. G. Pavithra, P. S. Kumar, V. Jailumar, P. S. Rajan, J. Ind. Eng. Chem., 75, 1-19 (2019).

4) Japan Environmental Council, "The State of the Environment in Asia 2006/2007", United Nations University Press (2010).

5) R. Vijayaraghavan, N. Vedaraman, M. Surianarayanan, D. R. MacFarlane, Talanta, 6, 1059-1062 (2006).

6) C. Li, B. Xin, W. Xu, Q. Zhang, J. Chem. Technol. Biotechnol., 82, 196-204 (2007).

7) A. Yilmaz, E. Yilmaz, M. Yilmaz, R. A. Bartsch, Dyes Pigments, 74, 54-59 (2007).

8) O. Gungor, A. Yilmaz, S. Memon, M. Yilmaz, J. Hazard. Mater., 158, $202-207$ (2008).

9) P. Pandit, S. Basu, Environ. Sci. Technol., 38, 2435-2442 (2004).

10) H. Noritomi, S. Tamai, H. Saito, S. Kato, Colloid Polym. Sci., 287, 455-459 (2009).

11) T. Kinugasa, H. Kashima, S. Kumeno, S. Tanaka, Y. Nishii, Sep. Sci. Technol., 47, 1957-1962 (2012). 
12) T. Kinugasa, T. Hashimoto, Y. Nishii, Solvent Extr. Res. Dev., Jpn., 22, 169-176 (2015).

13) P. Plucinski, W. Nitshe, Ber. Bunsenges. Phys. Chem., 93, 994-997 (1989).

14) T. Nishiki, I. Sato, A. Muto, T. Kataoka, Biochem. Eng. J., 1, 91-97 (1998).

15) M. Adachi, M. Harada, R. Nishita, A. Shioi, J. Phys. Chem., 99, 8722-8729 (1995).

16) M. M. Cardoso, R. M. C. Vigas, J. P. S. G. Crespo, Chem. Eng. Sci., 55, 2835-2847 (2000).

17) L. Dong, S. Huang, Q. Luo, X. Zhou, S. Zheng, Biochem. Eng. J., 46, 210-216 (2009).

18) S. H. Mohd-Setapar, H. Mat, S. N. Mohamad-Aziz, J. Taiwan Inst. Chem. Eng., 43, 685-695 (2012).

19) T. Kinugasa, S. Tanahashi, H. Takeuchi, Ind. Eng. Chem. Res., 30, 2470-2476 (1991).

20) T. Kinugasa, A. Kondo, S. Nishimura, Y. Miyauchi, Y. Nishii, K. Watanabe, H. Takeuchi, Colloids Surf. A: Physicochem. Eng. Asp., 204, 193-199 (2002).

21) T. Kinugasa, A. Hisamatsu, K. Watanabe, H. Takeuchi, J. Chem. Eng. Jpn., 27, 557-562 (1994). 